\title{
Costs of induced volatile production in maize
}

\author{
Maria Elena Hoballah, Tobias G. Köllner, Jörg Degenhardt and Ted C. J. Turlings
}

Hoballah, M. E., Köllner, T. G., Degenhardt, J. and Turlings, T. C. J. 2004. Costs of induced volatile production in maize. - Oikos 105: 168-180.

\begin{abstract}
Herbivore-induced plant volatiles have been shown to serve as indirect defence signals that attract natural enemies of herbivores. Parasitoids and predators exploit these plant-provided cues to locate their victims and several herbivores are repelled by the volatiles. Recently, benefits, in terms of plant fitness, from the action of the parasitoids were shown for a few systems. However, the cost of production of herbivore-induced volatiles for the plant remains unknown. Here, we estimate the fitness cost of the production of induced volatiles in maize, Zea mays. Plants were treated with regurgitant of Spodoptera littoralis or with the elicitor volicitin and we measured dry weight of plant parts at specific times after treatments. After a two-week treatment period, the dry-weight of leaves of induced plants was lower than that of un-induced plants, suggesting a metabolic cost for induced defence. However, maize plants seem to compensate for this loss during subsequent growth, since seed production at maturity was not different for unharmed plants and plants treated with caterpillar regurgitant. For volicitin treated plants a small but significant reduction in seed production was found. It is likely that the treatments also induced the production of other defence compounds, which will contribute to the cost. Yet, a comparison of six maize inbred lines with distinct differences in volatile emissions showed a strong correlation between the intensity of induced emissions and reduction in plant performance. An analysis of the terpenoids that accumulated in the leaves of the inbred lines revealed nonvolatilised compounds are constitutively present in maize and only the volatilised compounds are induced. Interestingly, the lines that released the largest amounts of induced volatiles also contained more of the non-volatile terpenoids. Based on these results and results from a previous study on the benefits of attracting parasitoids, we conclude that costs of induced volatile production in plants are counterbalanced by the benefits as long as natural enemies of the herbivores are present in the environment.
\end{abstract}

M. E. Hoballah and T. C. J. Turlings, Laboratory of Animal Ecology and Entomology, Inst. of Zoology, Univ. of Neuchâtel, Casc postale 2, CH-2007 Neuchâtel, Switzerland (ted.turlings@unine.ch). Present address for MEH: Inst. of Plant Sciences, Univ.of Bern, Altenbergrain 21, CH-3013 Bern, Switzerland. - T. G. Köllner and J. Degenhardt, Max Planck Institute for Chemical Ecology, Winzerlaer Strasse 10, DE-007745 Jena, Germany.

Natural enemies of herbivores can use volatiles that are produced by plants under herbivore attack to locate their prey (Whitman 1988, Vet and Dicke 1992, Turlings et al. 1995, Dicke and Vet 1999). These herbivoreinduced volatile emissions are suggested to function as an indirect defence for plants. Indeed, several field studies have shown that parasitism or predation was higher on plants that produced induced volatiles or on plants that were treated with synthetic volatiles, when compared to plants that did not produce or carry these volatiles (Titayavan and Altieri 1990, Drukker et al. 1995, Thaler 1999, Kessler and Baldwin 2001). It has also been shown that induced volatiles can repel herbivores and act as direct defence for the plants. For example, aphids (Bernasconi et al. 1998, Glinwood and Petterson 2000) and mites (Dicke and Dijkman 1992) are 
repelled by induced odours. Moreover, moths oviposit more on unharmed plants than on plants already damaged by caterpillars (Landolt 1993, De Moraes et al. 2001). Thus, volatiles produced by the plant after herbivore attack can have both direct and indirect defence effects. It is assumed that this defence through volatiles can only be maintained over evolutionary time if the plants benefit from induction. Evidence is mounting that insect herbivores impose selection on resistance traits in plants (Nunez-Farfan and Dirzo 1994, Mauricio and Rausher 1997, Mauricio 1998), and that those traits can also influence interactions between herbivores and their natural enemies (Simms and Fritz 1990). This is in contrast with the scenario proposed by Jermy (1993), that the evolution of insect-plant relationships results primarily from autonomous evolutionary events, namely from heritable functional changes within the insects nervous system that determine plant recognition and ultimately host plant specificity. Similarly, a nonfunctional accidental release of volatiles as by-products has also been hypothesised (Van der Meijden and Klinkhamer 2000). Reasons for why accidental release is not probable are discussed by Dicke and van Loon (2000), whereas Janssen et al. (2002) stress that even if volatiles releases were initially incidental, once natural enemies started using them to locate herbivores, natural selection must have operated on the plants to optimize the benefits from these signals.

Possible costs and benefits of induced defence have been discussed in detail (Turlings and Benrey 1998, Agrawal and Karban 1999). A benefit in form of increased seed production was demonstrated for the induced production of the direct defence in tobacco (Baldwin 1998) and in wild radish (Agrawal 1998). Recent experimental evidence suggests that plants may also benefit from attracting parasitoids (van Loon et al. 2000, Fritzsche Hoballah and Turlings 2001). These studies demonstrate a higher seed production in plants that are attacked by a caterpillar parasitized by a solitary braconid wasp than in plants attacked by unparasitized caterpillars.

Metabolic costs for induced volatile production are expected to be relatively high (Gulmon and Mooney 1986, Gerhenzon 1994a,b). Quantification of costs for induced production of secondary compounds in plants remains a topic of discussion and disagreement, but experimental studies are few. Some authors suggest high fitness costs of induced defence based on the optimal defence theory (Zangerl and Bazzaz 1992), while others suggest that the costs are relatively low (Dicke and Sabelis 1989). Experiments analysing induced direct defence costs are contradictory, depending on which system is examined (Brown 1988, Ryan 1992, Gianoli and Niemeyer 1997, Zangerl et al. 1997, Heil et al. 2000). Models that have been proposed for the analysis of the evolutionary stability of induced production of volatiles
(Sabelis and De Jong 1988, Godfray 1995) predict relatively high costs for the production of induced volatiles, but costs resulting from the biosynthesis of induced volatiles have never been experimentally demonstrated. Assessing costs of herbivore-induced volatiles may also help to confirm the indirect defence hypothesis (Janssen et al. 2002).

The aim of this paper is to assess direct fitness costs of the production of induced volatiles in maize plants. We used maize plants because they are very responsive to herbivore attack (Turlings et al. 1998b) and the odours they emit are known to be attractive to various parasitoids (Turlings et al. 1995). We induced plants to produce volatiles by treating them with regurgitant of Spodoptera littoralis (Lepidoptera: Noctuidae) or with volicitin, an elicitor that has been isolated from Spodoptera regurgitant (Alborn et al. 1997, 2000, Turlings et al. 2000). Induced odour emission in maize shows considerable variation of quality and quantity among different maize varieties and inbred lines (Gouinguené et al. 2001, Hoballah et al. 2002). We used maize inbred lines that emit either high or low amounts of volatiles after induction and correlated this difference with differences in growth parameters between control and induced plants of each specific inbred line. We hypothesised that maize plants incur limited metabolic cost of induced volatile production, which should be reflected in plant performance and in seed production under conditions where interactions with other organisms are excluded. The evaluation of fitness costs for the induced volatiles could be obscured by non-volatile metabolites that are also formed after herbivore attack and might be components of the direct defence. Genotypes that produce small amounts of volatiles could perhaps produce large quantities of non-volatile compounds, possibly investing more in direct defence. Therefore, we measured the induced production of both volatilised and stored terpenoids in different inbred lines.

\section{Material and methods}

\section{Plants and plant treatments}

Maize (Zea mays) of the two European varieties Delprim (Rothrist, Switzerland) and Pactol (Novartis seeds SA, France), and the inbred lines W401, F7, F113, F467, F1852 and Du101 from the collection of the Station de Génétique Végétale (Ferme du Moulon, INRA Gif-sur-Yvette, France, Degen et al., unpubl) were grown in plastic pots ( $6 \mathrm{~cm}$ high, $8 \mathrm{~cm}$ diameter) in fertilised commercial soil (Coop, Switzerland) in a climate chamber $\left(23^{\circ} \mathrm{C}, 60 \% \mathrm{RH}\right.$ and $16 \mathrm{~L}$ : $8 \mathrm{D}, 50000$ $\mathrm{lm} / \mathrm{m}^{2}$ ). To induce the plants to produce volatiles, we scratched the second and third leaf of each plant with a razor blade (an area of $2-3 \mathrm{~cm}^{2}$ per leaf) and $10 \mu \mathrm{l}$ regurgitant of Spodoptera littoralis (Boisd.) (Lepidop- 
tera: Noctuidae) was applied to each damaged site. The regurgitant had been collected from 4th and 5th instar of S. littoralis caterpillars fed with maize leaves (variety Delprim) and was kept at $-70^{\circ} \mathrm{C}$ until 10 minutes before application. Three additional control treatments were used: 1) plants that were left unharmed, 2) plants that were scratched as above, but only $10 \mu \mathrm{l}$ demineralised water was applied to the damaged sites and 3) plants that were only scratched.

\section{Volatile collections in the laboratory}

One week-old plants were placed in a climate chamber (Conviron, E95, Canada). The climate chamber was programmed at $17.5^{\circ} \mathrm{C}$ during light period and $20^{\circ} \mathrm{C}$ during dark period, $30 \% \mathrm{RH}$ and with a light intensity of $14500 \mathrm{~lm} / \mathrm{m}^{2}$ (light provided by 16 Sylvania $150 \mathrm{~W}$ VHO Cool White tubes and 12 Sylvania, $100 \mathrm{~W}$ Satin bulbs). We induced the plants, starting at the 3-4 leaf stage, seven times in total (each second day). For the experiment carried out with the variety Delprim, the volatiles of one plant per treatment were collected on the 5th, 6th and 7 th treatment day. During the experiment with the variety Pactol, volatiles of one plant per treatment were collected during all 7 periods of induction. For experiments with the varieties Delprim and Pactol, the plants used for the volatile collection were the same for each additional collection period.

With the inbred lines, only two treatments were carried out: scratching of the leaves only and scratching with addition of regurgitant. Five different inbred lines were used for this experiment, the volatile collections were carried out seven times, each time with a different plant.

Volatiles were collected from 5 plants simultaneously in an automated collection system (ARS, Gainesville, USA). For the first collection, when the plants were still small enough, six glass cylinders $(9.5 \mathrm{~cm}$ diameter, $54 \mathrm{~cm}$ high) were placed over the plants and rested on a Teflon disk consisting of two halves with a hole in the middle for the stem of the plant (Turlings et al. 1998b). For the following collections ${ }^{\circledR}$ Nalophan bags (diam. $150 \mathrm{~cm}$, Kalle Nalo GmbH, Wiesbaden, Germany) were placed over the plants as described by Turlings et al. (1998a). Air was pushed $\left(11 \mathrm{~min}^{-1}\right)$ through a charcoal filter and introduced from the top of each cylinder or ${ }^{\circledR}$ Nalophan bag over the plants. Traps containing the adsorbent Super-Q (25 mg, 80/100 MESH, Alltech, Deerfield State) were attached laterally at the base of each cylinder or on the bottom of the ${ }^{\circledR}$ Nalophan bag. Traps were connected via Tygon tubing to the flowmeters of the automated volatile collection apparatus and air was pulled out at $0.81 \mathrm{~min}^{-1}$ during 2 hours. The collection period was programmed with the use of the software TESS (Version 1.0, ARS, Gainesville, USA). The plants were treated in the dark for $7 \mathrm{~h}$ before the lights went on in the chamber. Collections started $3 \mathrm{~h}$ after the lights went on. After each collection, traps were rinsed with $150 \mu$ methylene chloride (Merck), and $200 \mathrm{ng}$ of n-octane (Sigma) and nonyl acetate (Sigma-Aldrich) were added as internal standards. One $3 \mu \mathrm{l}$ aliquot of the sample was injected on column, with an automated injection system into a Hewlett Packard model HP 6890 gas chromatograph equipped with a flame ionisation detector. The apolar EC-1 capillary column $(30 \mathrm{~m}, 0.25 \mathrm{~mm}$ intenal diam., $0.25 \mu \mathrm{m}$ film tickness, Alltech) was held at $50^{\circ} \mathrm{C}$ for 3 minutes and then programmed at $8^{\circ} \mathrm{C}$ per minute to $230^{\circ} \mathrm{C}$, where it was maintained for 9.5 minutes. The column was preceded by a deactivated retention gap (10 $\mathrm{m}, 0.25 \mathrm{~mm}$ internal diam., Connex USA) and a deactivated precolumn $(30 \mathrm{~cm}, 0.530 \mathrm{~mm}$ internal diam., Connex). Helium (24 cm/s) was used as carrier gas. HP Chemstation software was used to quantify all major components based on the detector response to the internal standards. To compare total amounts of volatiles collected among the three treatments, we used the non-parametric Kruskall Wallis test.

\section{Volatile collections in the field}

Some maize plants of the variety Delprim were transferred at the 4-leaf stage from the climate chamber and planted in a field plot near the University of Neuchâtel. Volatiles were collected in a similar way as in the laboratory. Plants were scratched and treated with buffer (phosphate buffer $\mathrm{pH} 8$ ) or volicitin (40 $\mathrm{ng} / \mu \mathrm{l}$ buffer) at approximately 10:00 am and several control plants were left unharmed. Volatiles were collected from 5:00 pm for $3 \mathrm{~h}$ in August 1998. In June 1999, plants were treated by scratching the leaves or by scratching and adding regurgitant at 10:00 am, while volatiles were collected 5 $\mathrm{h}$ after treatment for $2 \mathrm{~h}$. Just before each collection, plants were placed in ${ }^{\circledR}$ Nalophan bags. Purified air was pushed into the bags at the rate of $1.21 \mathrm{~min}^{-1}$ at the bottom part of each bag. The filter to trap the volatiles was placed at the upper part of the bag and air was pulled out from the bag through the filter at a rate of 0.8 $1 \mathrm{~min}^{-1}$ by the use of a vacuum pump. The airflow was controlled by a flowmeter (Aalborg, Orangenburg, NY, USA). For each subsequent collection, the same individual plants were used. The Kruskal Wallis test was used to test for differences in volatile emitted among treatments.

\section{Cost experiments under laboratory conditions}

Experiments with maize of the varieties Delprim and Pactol were carried out separately, and the five inbred lines were tested in a third experiment. After maize plants of the varieties Delprim or Pactol were treated 
seven times in total over two weeks (treated each second day), the leaves, stems and roots were dried in an oven at $80^{\circ} \mathrm{C}$ for 5 days. Subsequently, the dry weight of these plant parts was determined. For the inbred lines, only the dry weight of leaves was assessed after the 7-fold treatment. An ANOVA was used to test for differences in dry weights among the treatments. A Spearman Rank test was used to correlate the difference in dry weight and the difference in the total amount of volatiles released between the two treatments. In this way, we determined if the production of volatiles through regurgitant induction resulted in a loss of leaf tissue.

\section{Cost experiments in the field}

Maize plants of the variety Delprim were transferred from the climate chamber into a maize field near Marin (Switzerland) at an age of 2 weeks and treatments started the third week after planting. Three different treatments were carried out which were the same as used for the volatile collections in the field in 1998 and 1999. Short treatments were carried out for two weeks, on Monday, Wednesday and Friday of each week. The longer treatments lasted 6 weeks (with weeks 3 and 4 without treatment) in 1998 and 8 weeks (with weeks 3 and 6 without treatment) in 1999. For each treatment type and treatment period, 10 plants were used (a total of 50 plants). Treatments were carried out between 10:00 am and 1:00 pm. Experiments were repeated 2 times (2 blocks) in 1998, with a first treatment on June 8 and June 15, and 3 times (3 blocks) in 1999, starting the 7th, the 21 st and the $28 \mathrm{st}$ of June. Plants parts (leaves, stems, ears) were collected in October. Plants parts were dried at $80^{\circ} \mathrm{C}$ for 10 days and their weights were determined. An ANOVA was used to assess differences in dry weights among treatments for each year and each block.

\section{Analysis of volatile and non-volatile terpenoids in maize inbred lines}

We collected the volatiles from 2 week-old $( \pm 3$ days, all plants about the same height) unharmed plants and plants scratched and treated with $S$. littoralis regurgitant for each of the six different inbred lines $(n=4$ for each inbred line and treatment). Treatment of plants, collection of volatiles, and volatile analysis were done similar to the volatile collections in the laboratory. After the collection of volatiles, the plants were frozen at $-70^{\circ} \mathrm{C}$ for analysis of terpenoids inside the leaves of these plants (probably part of the direct defence of the plants). Frozen leaves $(3.3 \mathrm{~g})$ were placed in liquid $\mathrm{N}_{2}$ and crushed with a mortar. Pentane $(10 \mathrm{ml})$ was added to the leaf powder and mixed for 1 minute. The pentane extract was placed in a glass vial and shaken for $3 \mathrm{~h}$ at laboratory temperature and centrifuged for $5 \mathrm{~min}$
(2000 g). The supernatant was cleared with activated charcoal and again centrifuged to sediment the charcoal. Twenty $\mu \mathrm{l}$ iso-octane and $40 \mu \mathrm{l}$ nonyl acetate standard (20 ng $\mu^{-1}$ ) were added to the supernatant. Finally, the sample was concentrated under a $\mathrm{N}_{2}$ flow to a volume of $400 \mu 1$.

For analysis of the extracted terpenoids, $2 \mu \mathrm{l}$ of the samples was injected splitless (injector temperature $220^{\circ} \mathrm{C}$ ) into a Hewlett Packard model HP 6890 gas chromatograph coupled to a Hewlett Packard model HP 5973 quadrupole type mass selective detector (transfer line temperature $\left.230^{\circ} \mathrm{C}\right)$. The DB-5MS column $(30 \mathrm{~m}$, $0.25 \mathrm{~mm}$ internal diam., $0.25 \mu \mathrm{m}$ film tickness, J \& W Scientific) was held at $40^{\circ} \mathrm{C}$ for $3 \mathrm{~min}$ and than programmed at $5^{\circ} \mathrm{C}$ per min to $195^{\circ} \mathrm{C}$, and from $195^{\circ} \mathrm{C}$ to $300^{\circ} \mathrm{C}$ at $50^{\circ} \mathrm{C}$ per min. Helium $\left(2 \mathrm{ml} \mathrm{min}^{-1}\right)$ was used as carrier gas. An ANOVA and the Newman Keuls Student post-hoc test were used to test for differences in amounts of specific terpenoids among the inbred lines and between the unharmed and the treated plants. The Spearman test was used to correlate non-volatile terpenoids inside the plant and volatile terpenoids that were collected.

\section{Results}

\section{Volatile collections}

Contrary to our expectation, volatile emission by Delprim treated with regurgitant was not significantly different from volatile emission of plants that were scratched only (Fig. 1). However, there was a clear difference in total odours released between treated and unharmed plants (Kruskal Wallis, $\mathrm{P}=0.066, \chi^{2}=5.422$, $\mathrm{n}=3$, Fig. 1). Volatile emissions by Pactol were the lowest for unharmed plants and the highest for plants treated with regurgitant $\left(\mathrm{P}=0.004, \chi^{2}=11.099, \mathrm{n}=6\right)$, as expected (Fig. 1).

For the total amounts of odours released by Delprim in the field, there was also a significant difference between treated and unharmed plants $(1998, P=0.038$, $\chi^{2}=6.515, \mathrm{n}=8 ; 1999, \mathrm{P}=0.025, \chi^{2}=7.385, \mathrm{n}=4$; Fig. 2). Similar to the laboratory experiment with Delprim, no significant differences in odour emissions were detected in the field between scratched plants and plants treated with regurgitant.

\section{Plant performance in the laboratory}

For Delprim, a significantly lower dry weight of leaves, stems and roots was found in treated plants when compared to unharmed plants (ANOVA, $\mathrm{P}<0.0001$, $\mathrm{F}=18.098,18.357$ and 17.389 respectively, $\mathrm{n}=13$, Fig. $3)$. The treatments with water or regurgitant resulted only in a significant difference between the dry weights 


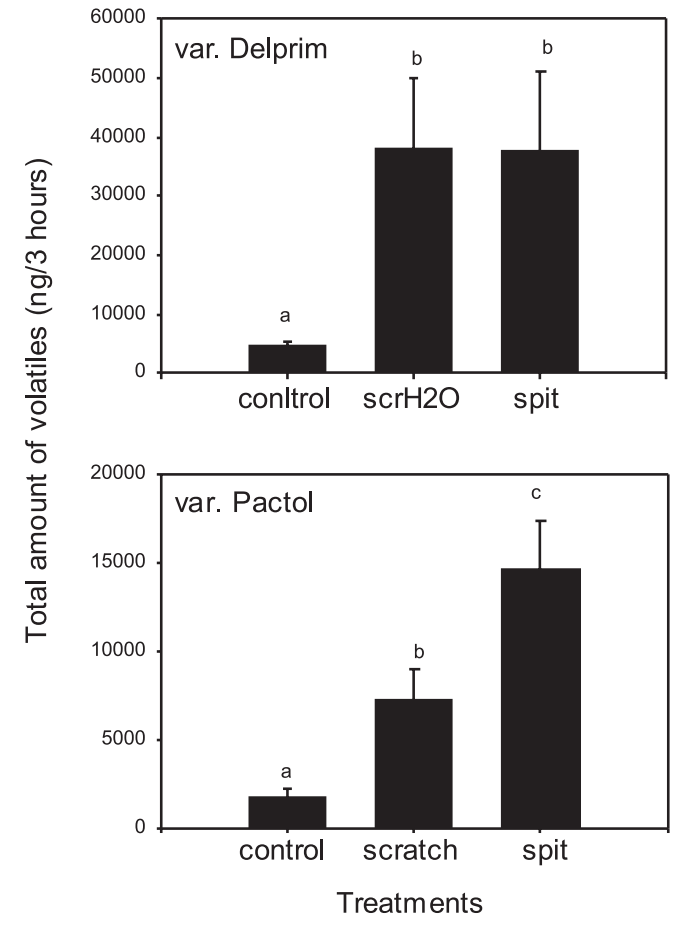

Fig. 1. Amount $(+\mathrm{SE})$ of volatiles released by 3 weeks old maize of the varieties Delprim and Pactol, after no treatments (control), scratching on two leaves (scratch); scratching on two leaves and damaged sites treated with water $(\mathrm{scrH} 2 \mathrm{O})$; scratching on two leaves and treated with regurgitant (spit). Different letters on bars indicate significant differences among treatments (Student-Newman-Keuls test after ANOVA).

of leaves and stems (Fig. 3). For Pactol, the dry weights of leaves, stems and roots showed smaller differences among the treatments (ANOVA, $\mathrm{P}=0.001, \mathrm{~F}=9.257$, $\mathrm{P}=0.006, \mathrm{~F}=6.226$ and $\mathrm{P}=0.139, \mathrm{~F}=2.128, \mathrm{n}=10$, respectively, Fig. 3). In fact, no significant differences in dry weight of leaves and stems were found between plants scratched and plants treated with regurgitant. The treated Pactol plants differed from the unharmed plants only in dry weight of leaf and stem.

The difference in dry weight between unharmed and treated inbred lines and the difference in volatiles released between these two treatments were positively correlated ( $\mathrm{P}=0.037 ; \mathrm{r}^{2}=0.900$, Fig. 4$)$, which is in accordance with a metabolic cost of volatile emission that results in reduced biomass production. If the results for Pactol are added to this analysis, the correlation is even stronger $\left(\mathrm{P}=0.019 ; \mathrm{r}^{2}=0.886\right.$, Fig. 4$)$, but the experiment with Pactol was done during a different period of time.

\section{Field experiments}

No differences were found between the dry weights of leaves and stems of mature plants, regardless of their
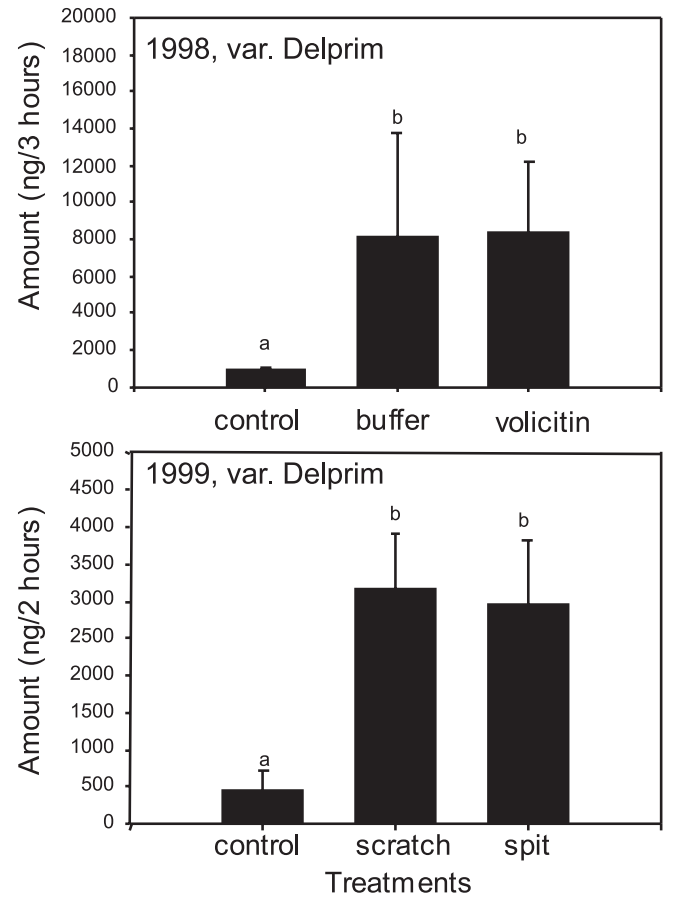

Fig. 2. Amount $(+\mathrm{SE})$ of volatiles released by maize plants, variety Delprim, on field collections in 1998 and 1999 after different treatments. unharmed plants (control), plants scratched on two leaves (scratch); plants scratched on two leaves and damaged sites treated with buffer (buffer); plants scratched on two leaves and treated with regurgitant (spit); plants scratched on two leaves and treated with volicitin (volicitin). Different letters on bars indicate significant differences among treatments (Student-Newman-Keuls test after ANOVA).

treatments in both years (ANOVA, 1998: stem $\mathrm{P}=0.225$, leaf $\mathrm{P}=0.0038$ not significant after Student Newman Keuls test $\mathrm{P}=0.054$, 1999: stem, $\mathrm{P}=0.531$, leaf, $\mathrm{P}=$ 0.306). However, for the dry weight of the seeds, a significative difference was found between treatments in the 1998 experiment (plot $1, \mathrm{P}=0.035, \mathrm{~F}=2.838$; plot 2, $\mathrm{P}=0.001, \mathrm{~F}=5.525$, Fig. 5). For plot 1 a significant difference was only found between control plants and plants treated with volicitin during the longer treatment period. For plot 2 seed production was significantly lower for the 4 weeks of treatment with both buffer and regurgitant when compared to the other treatments. No significant differences were found between control plants and plants treated for the shorter period in both plots (Fig. 5).

Even though the treatment of plants lasted for a longer period of six weeks in 1999, no significant differences were found among treatments for seed dry weight (plot $1, \mathrm{P}=0.723, \mathrm{~F}=0.518$; plot 2, $\mathrm{P}=0.709$, $\mathrm{F}=0.538$; plot $3, \mathrm{P}=0.422, \mathrm{~F}=0.993$, Fig. 6 ), but the trends were the same as in 1998. 
Fig. 3. Dry weight $(+\mathrm{SE})$ of leaves, stem and roots for maize plants of the varieties Pactol and Delprim after different treatments: unharmed plants (control), plants scratched on two leaves (scratch); plants scratched on two leaves and damaged sites treated with water (scrH2O); plants scratched on two leaves and treated with regurgitant (spit). Different letters on bars indicate significant differences among treatments (Student-Newman-Keuls test after ANOVA). var. Delprim

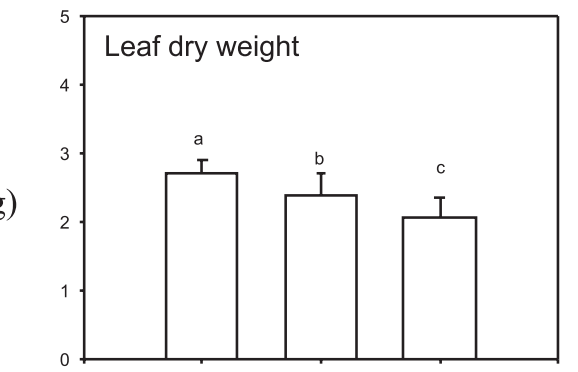

(g)

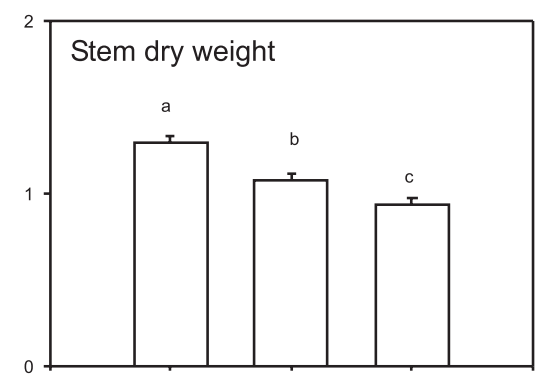

(g)

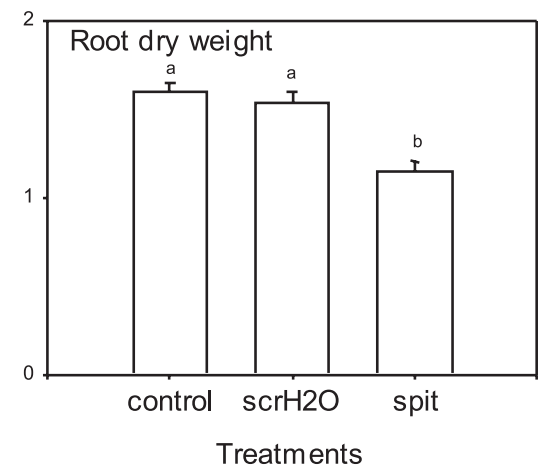

var. Pactol
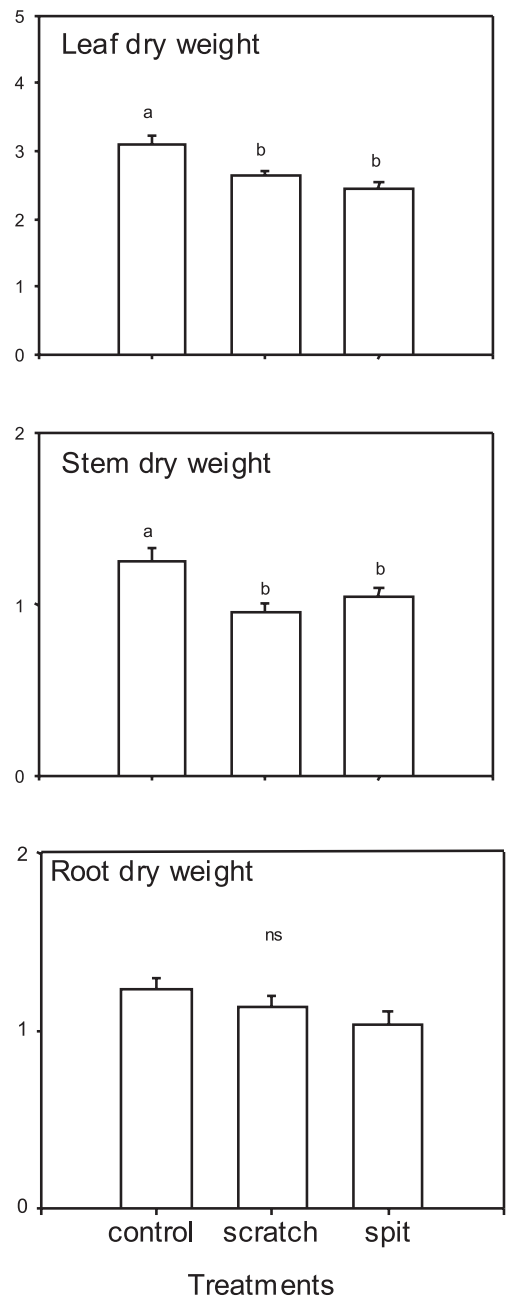

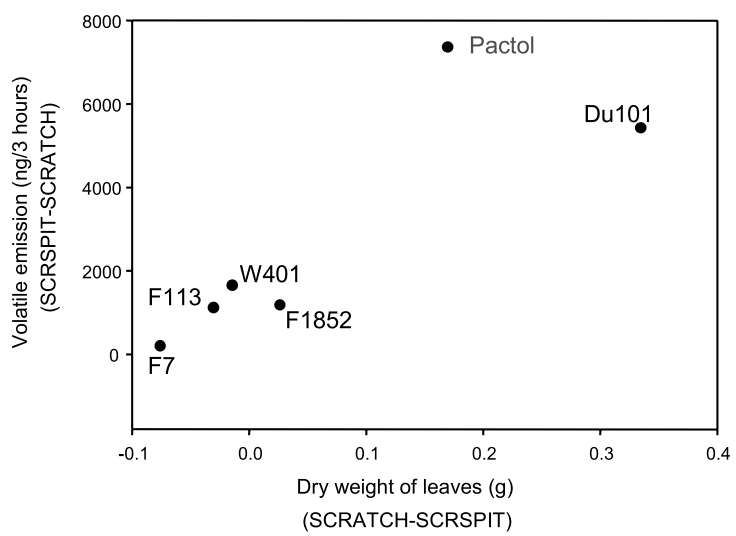

Fig. 4. Correlation between difference in volatiles released between plants scratched on two leaves with a razor blade and plants scratched on two leaves with addition of regurgitant and difference in dry weight of the leaves of plants treated in these two different ways.

\section{Analysis of volatile and non-volatile terpenoids from} maize inbred lines

Total volatiles collected from unharmed plants were generally very low, except for significantly higher emissions from inbred line $\mathrm{F} 476(\mathrm{P}<0.0001, \mathrm{~F}=40.276$, Fig. 7). Each inbred line released significantly more volatiles after treatment with damage and regurgitant $(\mathrm{P}=0.016-0.0001, \mathrm{~F}=11.180-68.210$, Table 1$)$, but the three lines F476, F1852 and Du101 emitted much higher levels of total volatiles than the lines W401, F7, F113 $(\mathrm{P}<0.0001, \mathrm{~F}=20.962$, Fig. 7). This result is consistant with previous data (Degen et al. unpubl.) that were used to select these lines.

Single volatile compounds that were emitted more by treated plants than by unharmed plants were classified as induced compounds (Table 1). Myrcene, $\mathrm{H}$-indole and $\beta$ caryophyllene were induced only in Du101, while (E)4,8-dimethyl-1,3,7-nonatriene was released by all in- 

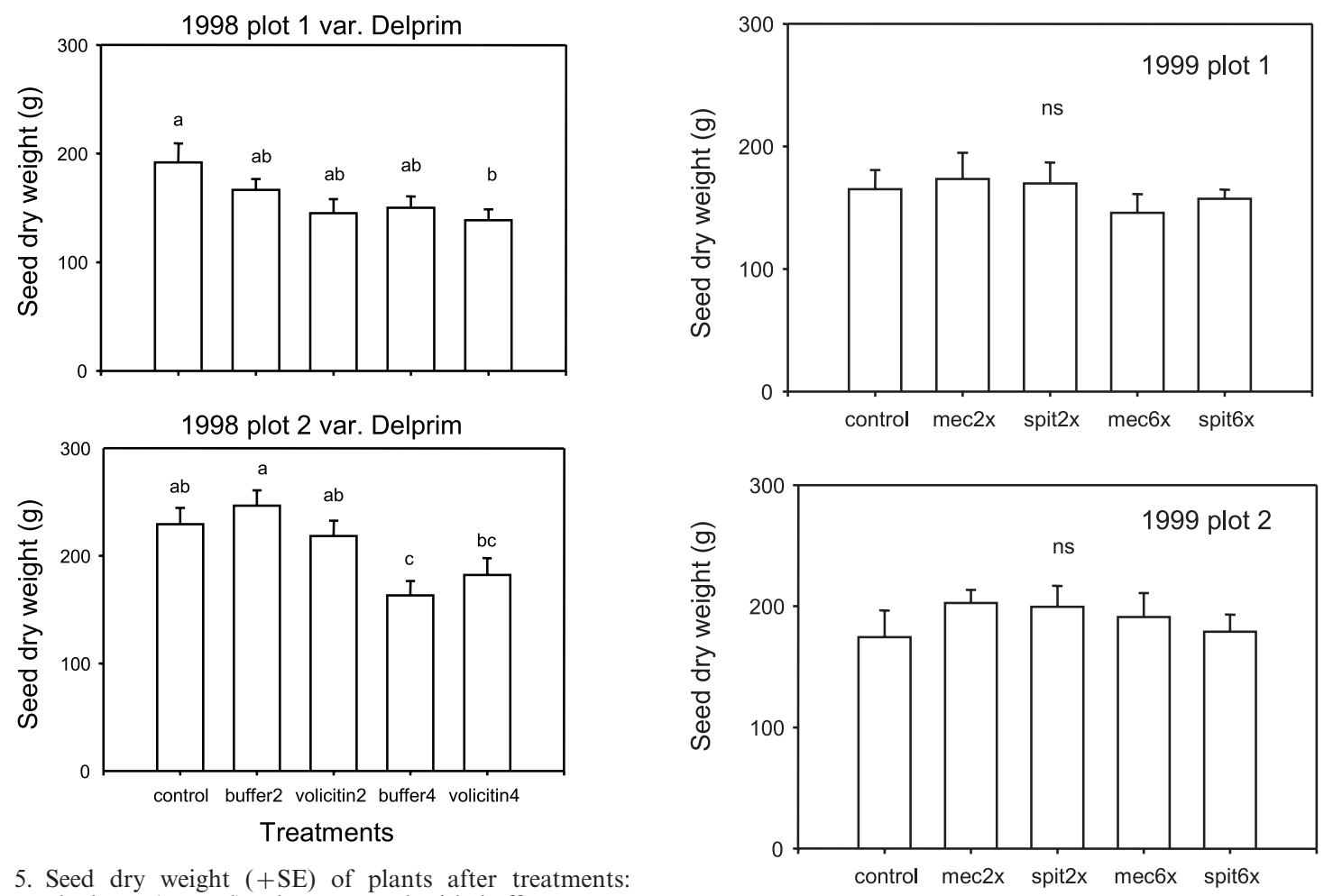

Fig. 5. Seed dry weight $(+\mathrm{SE})$ of plants after treatments: unharmed plants (control), plants treated with buffer on two damaged leaves for a period of two weeks (buffer $2 \times$ ), same as buffer $2 \times$ but treated with volicitin (volicitin $2 \times$ ), as for $2 \times$ but for a treatment period of 4 weeks (buffer $4 \times$ and volicitin $4 \times)$. Different letters on bars indicate significant differences among treatments (Student-Newman-Keuls test after ANOVA).

duced inbred lines except for W401. Linalool and (E)- $\beta$ farnesene were induced in 4 inbred lines (Du101, F1852, F476, F7, Table 1). (Z)-3-hexenyl acetate was only induced in the inbred lines W401 and F113. An exceptionally high release of linalool was found in unharmed F476 (Table 1).

The solvent extraction yielded a large number of compounds that were mostly sesquiterpenes (Table 1). Only in the lines Du101 and F113, there was a significant increase in the total amount of non-volatile terpenoids after treatment $(\mathrm{Du} 101, \mathrm{P}=0.004, \mathrm{~F}=$ 20.142; F113, $\mathrm{P}=0.001, \mathrm{~F}=40.832$, Fig. 7), indicating that non-volatilized terpenoids are produced only in some inbred lines after regurgitant treatment. Only the sesquiterpenes $\beta$-caryophyllene, (E)- $\alpha$-bergamotene and (E)- $\beta$-farnesene were identified in both the induced volatile blend and the extraction of the leaves. In unharmed plants of the inbred line F476, the total amounts of leaf terpenoids were significantly higher than in other lines $(\mathrm{P}=0.029, \mathrm{~F}=3.287$, Fig. 7). (E)- $\beta$ farnesene was the dominant induced terpenoid which was induced in 3 lines (Du101, F113, F7) and (E)- $\alpha$ bergamotene was induced in two inbred lines (Du101, F113). Finally, (E,E)-4,8,12-trimethyl-1,3,7,11-tridecatetraene and "unknown 17" were induced only in one

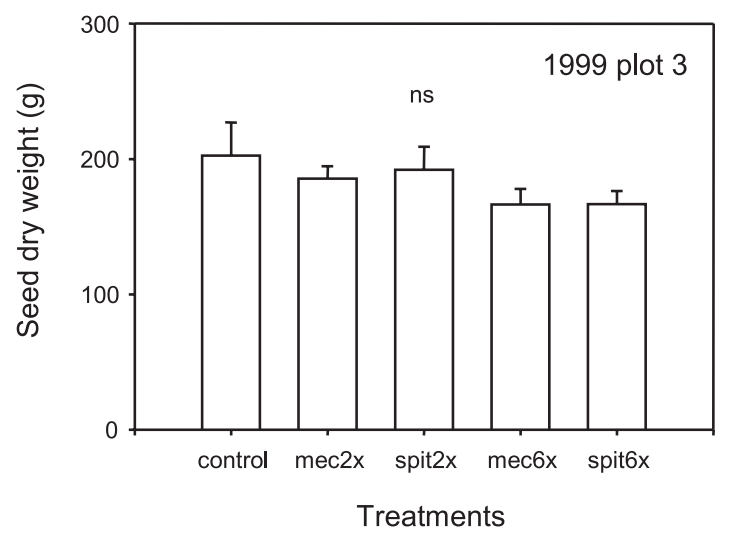

Fig. 6. Seed dry weight $( \pm \mathrm{SE})$ of plants after treatments: unharmed plants (control), two leaves scratched with a razor blade for a period of two weeks $(\operatorname{mec} 2 \times)$, same as mec $2 \times$ but with addition of volicitin on the damaged sites (spit $2 \times$ ), as for $2 \times$ but for a treatment period of 4 weeks (mec $4 \times$ and spit $4 \times$ ). ns: no significant differences among treatments (StudentNewman-Keuls test after ANOVA).

inbred line, W401 or Du101, respectively. There were significant differences among inbred lines in quantity of single non-volatile terpenoids extracted from unharmed and treated plants, with the exception of $\beta$-caryophyllene, (E)- $\alpha$-bergamotene and (E)- $\beta$-farnesene for unharmed plants and "unknown 20" for both treatments (Table 1).

No correlation was found between the amounts of constitutive and induced terpenoids of extracted leaves 
Fig. 7. Total amount of terpenoids collected from the headspace $(\mathrm{A}$ and $\mathrm{B})$ and extracted from leaves $(\mathrm{C}-\mathrm{D})$ $(+\mathrm{SE})$ from unharmed plants (unharmed) and plants treated with regurgitant (treated) of 6 different inbred lines. Different letters on bars indicate significant differences among treatments (Student-NewmanKeuls test after ANOVA)
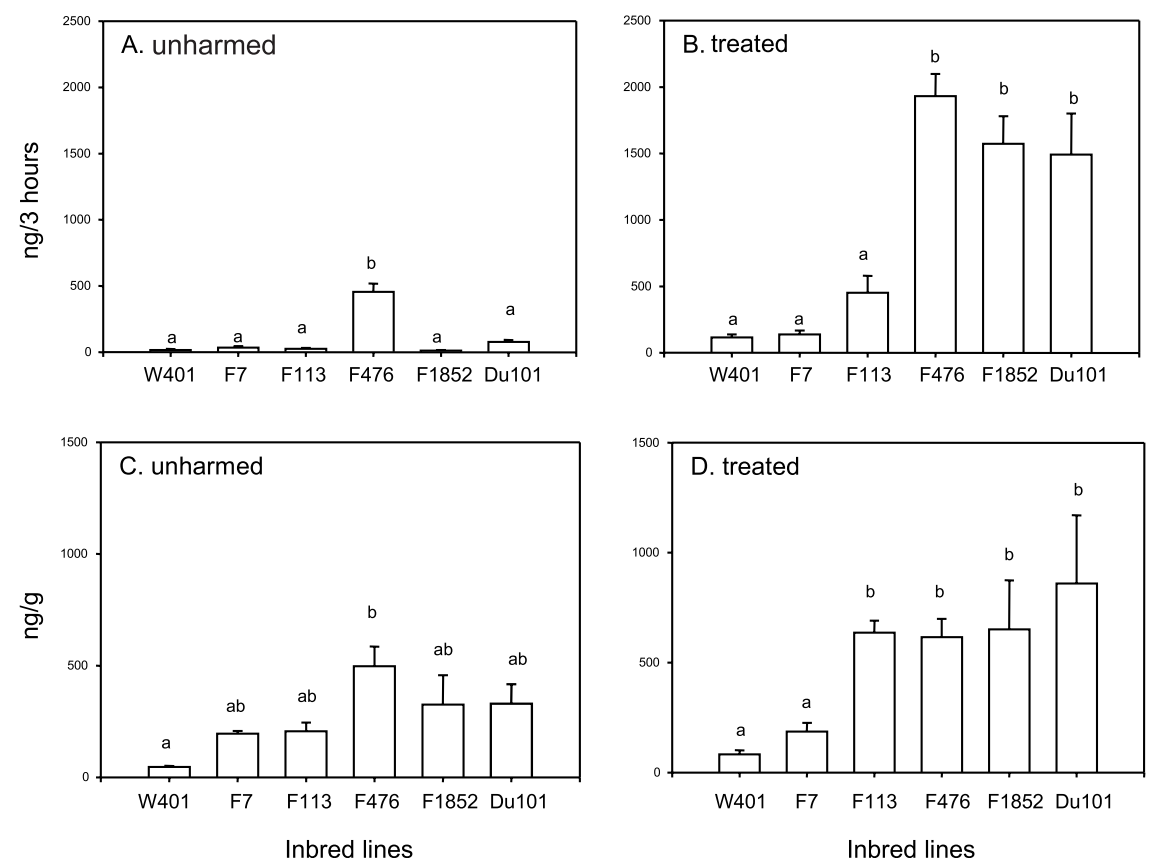

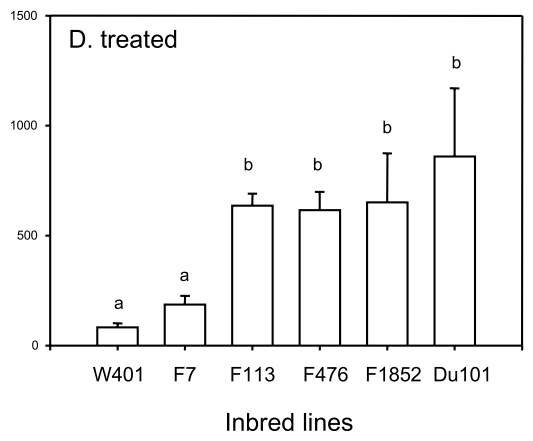

$\left(\mathrm{P}=0.156, \mathrm{r}^{2}=0.657, \mathrm{n}=6\right)$ and no correlation was found between the amounts of unharmed and induced volatile terpenoids $\left(P=0.704, r^{2}=0.200, n=6\right)$. Between the amount of constitutive non-volatile terpenoids and the amount of induced volatile terpenoids a significant positive correlation was found $(\mathrm{P}=0.005$, $\left.\mathrm{r}^{2}=0.943, \mathrm{n}=6\right)$. Between induced interfoliar terpenoids and volatile terpenoids of unharmed plants, the correlation was not significant $\left(P=0.787, r^{2}=-0.143\right.$, $\mathrm{n}=6)$.

The sesquiterpenes: $\beta$-caryophyllene, (E)- $\alpha$-bergamotene and (E)- $\beta$-farnesene were also identified in the volatile emission. For all three compounds, a correlation was found between the amounts of extracted and collected terpenoids after treatment $\left(\mathrm{P}=0.042, \mathrm{r}^{2}=\right.$ $0.829, \mathrm{n}=6$ for all three compounds). $\beta$-Caryophyllene was the only compound that showed a positive correlation between the amounts of volatile and extracted terpenes from leaves of control plants $\left(\mathrm{P}=0.015, \mathrm{r}^{2}=\right.$ $0.898, \mathrm{n}=6$ ) and a positive correlation between amounts of volatiles collected from treated plants and amounts extracted from leaves of control plants $\left(\mathrm{P}=0.021, \mathrm{r}^{2}=\right.$ $0.880, \mathrm{n}=6$ ).

\section{Discussion}

Volatile collections carried out in the field confirmed the laboratory results (Fig. 1): maize plants induced with the regurgitant of caterpillars produced a higher amount of volatiles than untreated plants (Fig. 2). The high release of volatiles by Delprim plants that were only mechani- cally damaged (Fig. 2) is not found in other varieties (Fig. 1, Turlings et al. 1990, Alborn et al. 1997, Turlings and Benrey 1998), the difference could be explained by a constitutive transcription of terpene synthase genes as found for at least one such gene in Delprim (Schnee et al. 2002).

The cost of induction in maize was only detectable in young plants soon after treatment, where we observed that unharmed plants had more leaf tissue than treated plants after a treatment period of 2 weeks (Fig. 3). A very low or no cost to the fitness (expressed in seed dry weight) was detected after the plant had matured (Fig. 5, 6). Hence, during maturation the treated plants compensated for the metabolic investment in early plant stages. Induced defence compounds are often produced in larger amounts in young plants or leaves. For example, terpenoids yields are higher in younger leaves of Hymenaea, were the attack of herbivores is more evident (Crankshaw and Langenheim 1981). In maize, induced volatile terpenoid production is also highest in younger plants (Gouinguené 2000, Turlings et al. 2001). A production of terpenoids that is limited to stages of the plant or parts of the plant that are most susceptible to herbivory will contribute to an overall saving of metabolic costs and is consistent with the optimal defence theory (Crankshaw and Langenheim 1981). Further costs are saved when defence compounds are only produced when a plant actually suffers from attack by a herbivore or a pathogen (Karban et al. 1997). That induced odour emissions bring about some costs can be concluded from the correlation shown in Fig. 4, which shows that the larger the difference in odour production 


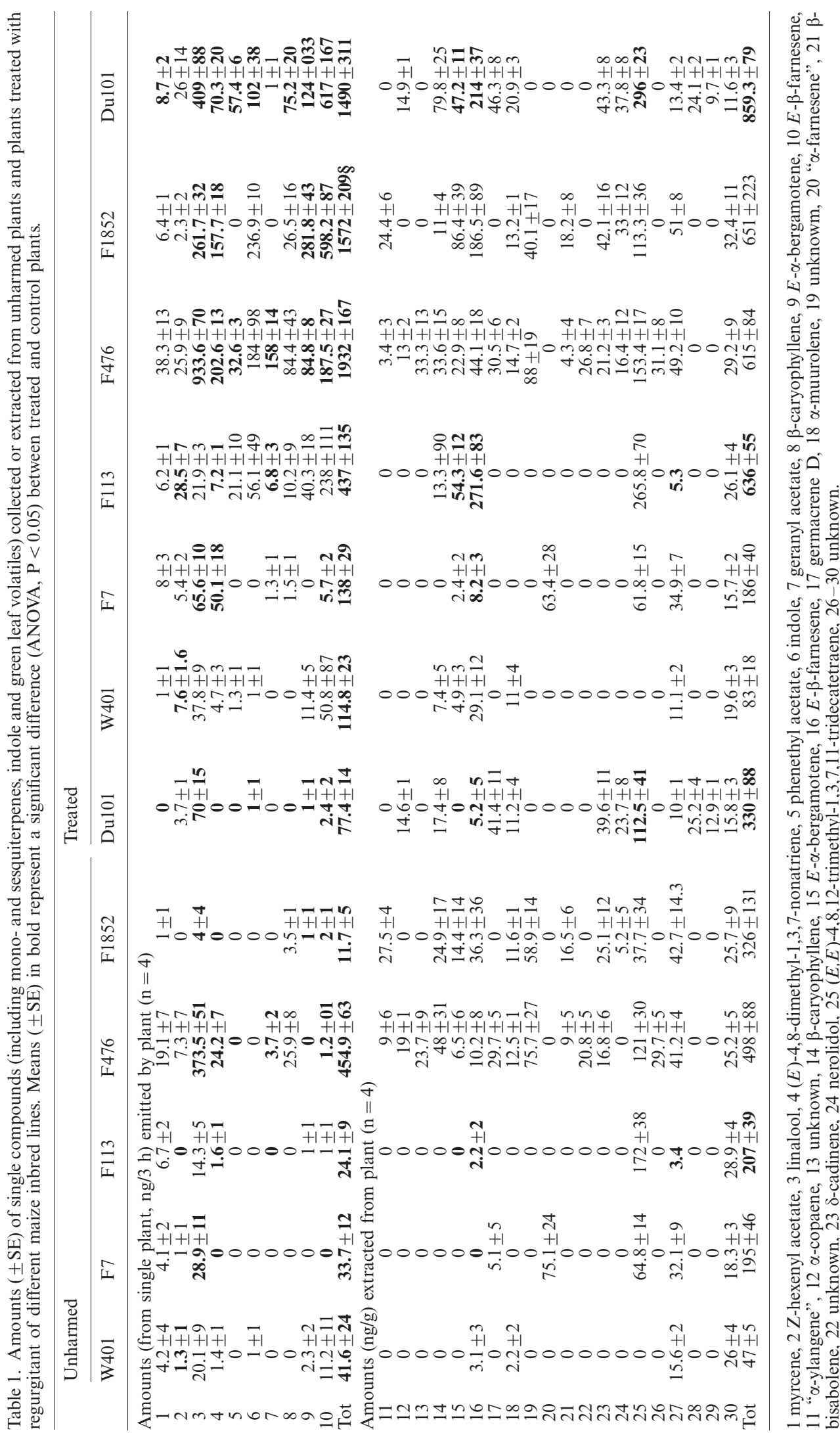


between treated plants and control plants, the larger the loss in biomass (dry weight) resulting from the treatment.

Maize plants (var. Delprim) attacked by a parasitized caterpillar early in development produce about 30\% more seed than plants attacked by a healthy caterpillar (Fritzsche Hoballah and Turlings 2001). Cost of induction in mature plants was a decrease in total seed dry weight of $27.7 \%$ and $20.1 \%$ in 1998 and $2.5 \%-17.7 \%$ in 1999 for the longer treatment period (Fig. 5, 6). This large variation between years and plots is also reflected in the production of volatiles (Fig. 2) and illustrates how the consequences for plant performance are dependent on the environment (Baldwin and Preston 1999, Van Dam and Baldwin 2001, Gouinguené and Turlings 2002, Koricheva 2002). However, the decrease in seed production as a result of the treatments was minimal, and clearly less than what the plant can potentially gain by attracting natural enemies of herbivores (Fritzsche Hoballah and Turlings 2001).

In our study, the surface of the leaves was damaged during treatment and as a consequence, the photosynthetic rate and growth rate of the plant were probably reduced. This would imply that the reduced production of seed mass was not only caused by an increased investment in volatiles or other induced compounds. The model of Gulmon and Mooney (1986) proposes that the cost, in terms of growth reduction, due to the allocation of carbon and energy for the synthesis of defensive compounds is proportional to photosynthetic rate and leaf allocation fraction. Differences in photosynthetic rate among maize varieties have been shown (Duncan and Hesketh 1968, Fischer and Palmer 1984). The production of induced terpenoids in maize plants is strongly light dependent (Turlings et al. 1995, Gouinguené and Turlings 2002), which was also found for cotton (Loughrin et al. 1994, Paré and Tumlinson 1997). If different maize varieties have different photosynthetic rates, this could result in a different capability to form induced defensive compounds. But since the growth of the studied inbred lines was comparable, the observed differences (Fig. 4, 7) are more likely the result of genetic variability in metabolic investment in the synthesis of volatiles. Variations in herbivore-induced volatiles was already detected among different European (Gouinguené et al. 2001) and different Mexican maize varieties (Hoballah et al. 2002). Such genetic variations in inducible responses have been found for 14 plantherbivore systems (Agrawal 2000).

Reduced growth rate after induction could also be caused by investment in the synthesis of (defence) compounds other than the terpenoids analysed in this study. In fact, the common defence hormone jasmonic acid is a growth inhibitor in some plants (Meyer et al. 1984) and is involved in various defence processes (Reymond and Farmer 1998), including the emission of volatiles (Paré and Tumlinson 1999). In tomato and potato, jasmonic acid also induces the accumulation of proteinase inhibitors (Pena-Cortés et al. 1993). Interestingly, fitness costs of jasmonate-induced defence could be reduced by induced ethylene burst in tobacco plants (Voelckel et al. 2001). Jasmonic acid itself is also an elicitor of the release of volatile compounds after wounding of a plant (Paré and Tumlinson 1999). Clearly, investment in the production of other non-volatile defence compounds may have contributed to the lower dry weight of treated plants in our study. Yet, the contribution of volatiles to this cost is apparent from Fig. 4 and the overall conclusion that this cost is limited in comparison to potential ecological benefits (Fritzsche Hoballah and Turlings 2001) is valid even if we ignore the induction of non-volatile compounds.

Differences in the regulation of genes and pathways for the production of secondary compounds between constitutive and induced defence or between direct and indirect defence are poorly understood. There is some evidence that induced and constitutive defence compounds are positively correlated (Campbell and Duffey 1979, Björkman and Anderson 1990, Zangerl and Berenbaum 1993, Siemens and Mitchell-Olds 1998, Scutareanu et al. 1999, Agrawal 2000). Only in two systems a negative or lack of correlation between constitutive and induced defence was observed (Brody and Karban 1992, Traw 2002). In our case, a positive correlation was found between volatile terpenoids released after induction and terpenoids extracted from leaves of unharmed plants. This means that in maize, a high presence of constitutive terpenoids that may serve in direct defence is linked with large amounts of induced volatile terpenoids that may serve in indirect defence. Indeed, Spodoptera caterpillars feeding on high volatileemitting maize plants gained less weight than caterpillars feeding on low volatile emitting plants (Thomas Degen pers. comm.).

The three dominating terpenoids detected in maize leaf extracts were also the major terpenoids released in the atmosphere after induction ( $\beta$-caryophyllene, $(E)-\alpha-$ bergamotene and (E)- $\beta$-farnesene, Table 1$)$. For all three compounds, a positive correlation was found between their concentration in the leaves of induced plants and the amounts at which they were released as volatiles after treatment. It may be that terpenoids accumulate in the leaves of induced plants from where they are being released in the atmosphere. These terpenoids may act simultaneously as direct and indirect defence for the plant. For example, caryophyllene affects mortality and growth rate of Spodoptera exigua and quantitative variation in caryophyllene content among Hymenaea cultivars result in differential resistance (Crankshaw and Langenheim 1981). It is also known that caryophyllene can attract predators such as the green lacewing (Flint et al. 1979). $\beta$-Caryophyllene may be produced by another 
pathway than the other two major terpenoids, since correlation between the amount inside unharmed plants and the amount released by treated plants was significant only for this compound. That caryophyllene production is independent of bergamotene and farnesene production may also be evident from the fact that there is a difference in timing of their respective production (Turlings et al. 1998b, Gouinguené 2000). In cotton, de novo synthesis of farnesene was demonstrated with ${ }^{13} \mathrm{C}$ labelling, in contrast only low metabolic turnover was found for caryophyllene (Paré and Tumlinson 1997).

\section{Conclusions}

Domestication is often associated with loss of defences (Loughrin et al. 1995, Rosenthal and Dirzo 1997). For cotton it has been found that a naturalized variety had a 7-fold higher production of induced volatile amounts than cultivated varieties (Loughrin et al. 1995). However, for maize the release of volatiles is similar for cultivated varieties and its wild ancestors (Gouinguené et al. 2001). Optimal defence theory predicts that organisms evolve to allocate defences in a way that maximises individual inclusive fitness and that these defences are costly (Rhoades 1979). Therefore, poorly defended individuals have higher fitness than well-defended individuals when enemies are absent (Rhoades 1979). The fact that younger maize plants release higher quantities of induced volatiles fits the first prediction of this theory. Our findings that plants that were treated to release volatiles showed a decrease in leaf-mass gain (Fig. 4) is congruent with the second prediction of the theory. However, overall fitness was not reduced as the treated plants compensated for these losses over time and produced as much seed as control plants. In conclusion, there appears to be some cost of induced volatile production in maize plants but it is only in part detectable in the reproductive output of a plant. Benefits of releasing volatiles when under attack by herbivore can be considerable, but only in environments where natural enemies of the herbivores will be present and responsive to the odours (Fritzsche Hoballah and Turlings 2001).

Acknowledgements - We thank Martine Rahier for motivational support and laboratory infrastructure. Syngenta (Basel) supplied us with Spodoptera littoralis eggs and caterpillars. This study was supported by grants from the Swiss Centre of International Agriculture (ZIL, ETH-Zurich) and the Swiss National Science Foundation (grants $31-46237-95$ and 3144459-95)

\section{References}

Agrawal, A. A. 1998. Induced responses to herbivory and increased plant performance. - Science 279: 1201-1202.

Agrawal, A. A. 2000. Induced plant defence: evolution of induction and adaptive phenotypic plasticity. - In: Agrawal,
A. A., Tuzan, S. and Bent, E. (eds), Induced plant defences against pathogens and herbivores: biochemistry, ecology, and agriculture. APS Press, pp. 251-268.

Agrawal, A. A. and Karban, R. 1999. Why induced defenses may be favored over constitutive strategies in plants. - In: Tollrian, R. and Harvell, C. D. (eds), The ecology and evolution of inducible defenses. Princeton Univ. Press, pp. $45-61$.

Alborn, H. T., Turlings, T. C. J., Jones, T. H. et al. 1997. An elicitor of plant volatiles from beet armyworm oral secretion. - Science 276: 945-949.

Alborn, H. T., Jones, T. H., Stenhagen, G. S. et al. 2000. Identification and synthesis of volicitin and related components from beet armyworm oral secretions. - J. Chem. Ecol. 26: $203-220$.

Baldwin, I. T. 1998. Jasmonate-induced responses are costly but benefit plants under attack in native populations. - Proc. Natl Acad. Sci. 95: 8113-8118.

Baldwin, I. T. and Preston, C. A. 1999. The eco-physiological complexity of plant responses to insect herbivores. - Planta 208: $137-145$.

Bernasconi, M. L., Turlings, T. C. J., Ambrosetti, L. et al. 1998. Herbivore-induced emissions of maize volatiles repel the corn leaf aphid, Rhopalosiphum maidis. - Entomol. Exp. Appl. 87: 133-142.

Björkman, C. and Anderson, D. B. 1990. Trade - off among antiherbivore defences in a South American blackberry (Rubus bogotensis). - Oecologia 85: 247-249.

Brody, A. K. and Karban, R. 1992. Lack of trade-off between constitutive and induced defences among varieties of cotton. - Oikos 65: 301-306.

Brown, D. G. 1988. The cost of plant defence: an experimental analysis with inducible proteinase inhibitors in tomato. - Oecologia 76: 467-470.

Campbell, B. C. and Duffey, S. S. 1979. Tomatine and parasitic wasps: potential incompatibility of plant antibiosis with biological control. - Science 205:

Crankshaw, D. R. and Langenheim, J. H. 1981. Variation in terpenes and phenolics through leaf development in Hymenaea and its possible significance to herbivory. - Biochem. Syst. Ecol. 9: 115-124.

De Moraes, C., Mescher, M. C. and Tumlinson, J. H. 2001. Caterpillar-induced nocturnal plant volatiles repel conspecific females. - Nature 410: 577-580.

Dicke, M. and Sabelis, M. W. 1989. Does it pay plants to advertize for bodyguards? Towards a cost-benefit analysis of induced synomone production. - In: Lambers, H. (ed.), Causes and consequences of variation in growth rate and productivity of higher plants. SPB Academic Publishing, pp. $341-358$.

Dicke, M. and Dijkman, H. 1992. Induced defence in detached uninfested plant leaves: effects on behaviour of herbivores and their predators. - Oecologia 91: 554-560.

Dicke, M. and Vet, L. E. M. 1999. Plant-carnivore interactions: evolutionary and ecological consequences for plant, herbivore and carnivore. - In: Olff, H., Brown, V. K. and Drent, R. H. (eds), Herbivores: between plants and predators. Blackwell Science, pp. 483-520.

Dicke, M. and van Loon, J. J. A. 2000. Multitrophic effects of herbivore-induced plant volatiles in an evolutionary context. - Entomol. Exp. Appl. 97: 237-249.

Drukker, B., Scutarenanu, P. and Sabelis, M. W. 1995. Do anthocorid predators respond to synomones from Psyllainfested pear trees under field conditions? - Entomol. Exp. Appl. 77: 193-203.

Duncan, W. G. and Hesketh, J. D. 1968. Net photosynthetic rates, relative leaf growth rates, and leaf numbers of 22 races of maize grown at eight temperatures. - Crop Sci. 8: 670674.

Fischer, K. S. and Palmer, A. F. E. 1984. Tropical maize. - In: Goldsworthy, P. R. and Fisher, N. M. (eds), The physiology of tropical field crops. John Wiley \& Sons Ltd, pp. 213-248. 
Flint, H. M., Salter, S. S. and Walters, S. 1979. Caryophyllene: an attractant for the green lacewing. - Environ. Entomol. 8: $1123-1125$.

Fritzsche Hoballah, M. E. and Turlings, T. C. J. 2001. Experimental evidence that plants under caterpillar attack may benefit from attracting parasitoids. - Evol. Ecol. Res. 3: $1-13$.

Gerhenzon, J. 1994a. The cost of chemical defence against herbivory: a biochemical perspective. - In: Bernays, E. A. (ed.), Insect plant interactions. CRC Press, pp. 105-173.

Gerhenzon, J. 1994b. Metabolic costs of terpenoid accumulation in higher plants. - J. Chem. Ecol. 20: 1281-1328.

Gianoli, E. and Niemeyer, H. M. 1997. Lack of costs of herbivory-induced defences in a wild wheat: integration of physiological and ecological approaches. - Oikos 80: 269275.

Glinwood, R. T. and Petterson, J. 2000. Change in response of Rhopalosiphum padi spring migrants to the repellent winter host component methyl salicylate. - Entomol. Exp. Appl. 94: $325-330$.

Godfray, H. C. J. 1995. Communication between the first and third trophic levels: an analysis using biological signalling theory. - Oikos 72: 367-374.

Gouinguené, S. 2000. Specificity and variability of induced volatile. - Ph.D. thesis, Dept of Zoology, Univ. of Neuchâtel.

Gouinguené, S. P. and Turlings, T. C. J. 2002. The effects of abiotic factors on induced volatile emissions in corn plants. - Plant Physiol. 129: 1296-1307.

Gouinguené, S., Degen, T. and Turlings, T. C. J. 2001. Variability in herbivore-induced odour emissions among maize cultivars and their wild ancestors (teosinte). - Chemoecology 11: 9-16.

Gulmon, S. L. and Mooney, H. A. 1986. Costs of defence and their effects on plant productivity. - In: Givnnish, T. J. (ed.), On the economy of plant form and function. Cambridge Univ. Press, pp. 681-698.

Heil, M., Hilpert, A., Kaiser, W. et al. 2000. Reduced growth and seed set following chemical induction of pathogen defence: does systemic aquired resistance (SAR) incur allocation costs? - J. Ecol. 88: 645-654.

Hoballah Fritzsche, M. E., Tamò, C. and Turlings, T. C. J. 2002. Differential attractiveness of induced odors emitted by eight maize varieties for the parasitoid Cotesia marginiventris: is quality or quantity important? - J. Chem. Ecol. 28: 951968.

Janssen, A., Sabelis, M. W. and Bruin, J. 2002. Evolution of herbivore-induced plant volatiles. - Oikos 97: 134-138.

Jermy, T. 1993. Evolution of insect-plant relationships - a devil's advocate approach. - Entomol. Exp. Appl. 66: 3-12.

Karban, R., Agrawal, A. A. and Mangel, M. 1997. The benefits of induced defences against herbivores. - Ecology 78: $1351-$ 1355.

Kessler, A. and Baldwin, J. T. 2001. Defensive function of herbivore-induced plant volatile emissions in nature. - Science 291: 2141-2144.

Koricheva, J. 2002. Meta-analysis of sources of variation in fitness costs of plant antiherbivore defenses. - Ecology 83: $176-190$.

Landolt, P. J. 1993. Effects of host plant leaf damage on cabbage looper moth attraction and oviposition. - Entomol. Exp. Appl. 67: 79-85.

Loughrin, J. H., Manukian, A., Heath, R. R. et al. 1994. Diurnal cycle of emission of induced volatile terpenoids by herbivore-injured cotton plants. - Proc. Natl Acad. Sci. 91: $11836-11840$

Loughrin, J. H., Manukian, A., Heath, R. R. et al. 1995. Volatiles emitted by different cotton varieties damaged by feeding beet armyworm larvae. - J. Chem. Ecol. 21: 12171227.

Mauricio, R. 1998. Costs of resistance to natural enemies in field populations of the annual plant Arabidopsis thaliana. - Am. Nat. 151: 20-28.
Mauricio, R. and Rausher, M. D. 1997. Experimental manipulation of putative selective agents provides evidence for the role of natural enemies in the evolution of plant defense. - Evolution 51: 1435-1444.

Meyer, A., Miersch, O., Büttner, C. et al. 1984. Occurence of the plant growth regulator jasmonic acid in plants. - J. Plant Growth Reg. 3: 1-8.

Nunez-Farfan, J. and Dirzo, R. 1994. Evolutionary ecology of Datura stramonium L. in central Mexico - natural-selection for resistance to herbivorous insects. - Evolution 48: 423436.

Paré, P. W. and Tumlinson, J. H. 1997. Induced synthesis of plant volatiles. - Nature 385: 30-31.

Paré, P. W. and Tumlinson, J. H. 1999. Plant volatiles as a defence against insect herbivores. - Plant Phys. 121: 325331.

Pena-Cortés, H., Albrecht, T., Prat, S. et al. 1993. Aspirin prevents wound-induced gene expression in tomato leaves by blocking jasmonic acid biosynthesis. - Planta 191: 123-128.

Reymond, P. and Farmer, E. E. 1998. Jasmonate and salicylate as global signals for defense gene expression. - Curr. Op. Plant Biol. 1: 404-411.

Rhoades, D. F. 1979. Evolution of plant chemical defence against herbivores. - In: Rosenthal, J. P. and Janzen, D. H. (eds), Herbivores: their interaction with secondary plant metabolites. Academic Press, pp. 3-54.

Rosenthal, J. P. and Dirzo, R. 1997. Effects of life history, domestication and agronomic selection on plant defence against insects: evidence from maizes and wild relatives. - Evol. Ecol. 11: 337-355.

Ryan, C. A. 1992. The search for the proteinase inhibitorinducing factor, PIIF. - Plant Mol. Biol. 19: 123-133.

Sabelis, M. W. and De Jong, M. C. M. 1988. Should all plants recruit bodyguards? Conditions for a polymorphic ESS of synomone production in plants. - Oikos 53: 247-252.

Schnee, C., Köllner, T. G., Gershenzon, J. et al. 2002. The maize gene terpene synthase 1 encodes a sesquiterpene synthase catalyzing the formation of (E)-( $\beta$-farnesene, (E)-nerolidol, and (E, E)-farnesol after herbivore damage. - Plant Physiol. 130: 2049-2060.

Scutareanu, P., Ma, Y., Claeys, M. et al. 1999. Induction of a pcoumaroyl trihydroxy triterpene acid in Psylla-infested and mechanically damaged trees. - J. Chem. Ecol. 25: $2177-$ 2191.

Siemens, D. H. and Mitchell-Olds, T. 1998. Evolution of pestinduced defences in Brassica plants: tests of theory. - Ecology 79: 632-646.

Simms, E. L. and Fritz, R. S. 1990. The ecology and evolution of host-plant resistance to insects. - Trends Ecol. Evol. 5: $356-360$.

Thaler, J. S. 1999. Jasmonate-inducible plant defences cause increased parasitism of herbivores. - Nature 399: 686-688.

Titayavan, M. and Altieri, M. A. 1990. Synomone-mediated interactions between the parasitoid Diaeretiella rapae and Brevicoryne brassicae under field conditions. - Entomophaga 35: 499-507.

Traw, M. B. 2002. Is induction response negatively correlated with constitutive resistance in black mustard? - Evolution 56: $2196-2205$.

Turlings, T. C. J. and Benrey, B. 1998. Effects of plant metabolites on the behavior and development of parasitic wasps. - Ecoscience 5: 321-333.

Turlings, T. C. J., Tumlinson, J. H. and Lewis, W. J. 1990. Exploitation of herbivore-induced plant odours by hostseeking parasitic wasps. - Science 250: 1251-1253.

Turlings, T. C. J., Loughrin, J. H., McCall, P. J. et al. 1995. How caterpillar-damaged plants protect themselves by attracting parasitic wasps. - Proc. Natl Acad. Sci. 92: 4169-4174.

Turlings, T. C. J., Bernasconi, M., Bertossa, R. et al. 1998a. The induction of volatile emissions in maize by three herbivore species with different feeding habits: possible consequences for their natural enemies. - Biol. Control 11: 122-129. 
Turlings, T. C. J., Lengwiler, U. B., Bernasconi, M. L. et al. 1998b. Timing of induced volatile emissions in maize seedlings. - Planta 207: 146-152.

Turlings, T. C. J., Alborn, H. T., Loughrin, J. H. et al. 2000. Volicitin, an elicitor of maize volatiles in oral secretion of Spodoptera exigua: isolation and bioactivity. - J. Chem. Ecol. 26: 189-202.

Turlings, T. C. J., Gouinguené, S., Degen, T. et al. 2001. The chemical ecology of plant-caterpillar-parasitoid interactions. - In: Tscharntke, T. and Hawkins, B. (eds), Multitrophic level interactions. Cambridge Univ. Press, pp. 148-173.

Van Dam, N. M. and Baldwin, I. T. 2001. Competition mediates costs of jasmonate-induced defences, nitrogen acquisition and transgenerational plasticity in Nicotiana attenuata. -Funct. Ecol.14: 406-415.

Van der Meijden, E. and Klinkhamer, P. G. L. 2000. Conflicting interests of plants and the natural enemies of herbivores. - Oikos 89: 202-208.

van Loon, J. J. A., Boer, J. G. and Dicke, M. 2000. Parasitoidplant mutualism: parasitoid attack of herbivore increases plant reproduction. - Entomol. Exp. Appl. 97: 219-227.
Vet, L. E. M. and Dicke, M. 1992. Ecology of infochemical use by natural enemies in a tritrophic context. - Annu. Rev. Entomol. 37: 141-172.

Voelckel, C., Schittko, U. and Baldwin, I. T. 2001. Herbivoreinduced ethylene burst reduces fitness costs of jasmonateand oral secretion-induced defences in Nicotiana attenuata. - Oecologia 127: 274-280.

Whitman, D. W. 1988. Allelochemicals interactions among plants, herbivores, and their predators. - John Wiley and Sons.

Zangerl, A. R. and Bazzaz, F. A. 1992. Theory and pattern in plant defence allocation. - In: Fritz, R. S. and Simms, E. L. (eds), Plant resistance to herbivores and pathogens: ecology, evolution and genetics. Univ. of Chicago Press, pp. $363-391$.

Zangerl, A. R. and Berenbaum, M. R. 1993. Plant chemistry, insect adaptations to plant chemistry, and host plant utilization patterns. - Ecology 74: 47-54.

Zangerl, A. R., Arntz, A. M. and Berenbaum, M. R. 1997. Physiological price of an induced chemical defense: photosynthesis, respiration, biosynthesis, and growth. - Oecologia 109: 433-441. 